\title{
Engaged Teachers Scale for Special Educational Needs Teachers in Indonesia: A Rasch Model Approach
}

\author{
Ika Febrian Kristiana ${ }^{1,{ }^{*}}$ Ermida Simanjuntak $^{2}$ \\ ${ }^{I}$ Fakultas Psikologi, Universitas Diponegoro, Jl. Prof. Soedarto, SH, Kampus Undip Tembalang, Semarang, \\ Indonesia 50275 \\ ${ }^{2}$ Faculty of Psychology, Widya Mandala Catholic University Surabaya, Jl. Raya Kalisari Selatan No 1 Pakuwon \\ City, Surabaya, Indonesia, Indonesia 60112 \\ *Corresponding author. Email: ika.f.kristiana@gmail.com
}

\begin{abstract}
Engaged Teachers Scale (ETS) is currently the only scale measuring teacher engagement. Although it has good validity when it was developed by Klassen et al (2013) in the UK, but there were not many have reported its validity when used in different cultural settings. Therefore, the ETS adaptation process is needed to apply the scale in different cultural contexts. Although the main tasks of teachers are similar in various countries, the teachers' responsibility in handling special needs students should be considered in applying this scale for teachers in inclusive education. This study aims to adapt ETS to the context of inclusive education in Indonesia. The study participants were 340 primary inclusive school teachers (female $=76 \%$; SD age $=1.02$; SD teaching exp. $=.82)$ from two cities in Indonesia. The result showed that the ETS had high values of the person and item interaction $(\alpha=.94)$. The quality of the item and person is good enough with person reliability $=.72$ and item reliability $=.93$. The average person logit value $=4.49$ logit means that many people agree on all items. Separation value is 2.45 that indicates the two groups of teachers based on the degree of engagement. There were 3 misfit items with MNSQ score $(.5<$ MNSQ <1.5), those are item number 4,10 , and 12 . The value of raw variance data is $45.4 \%$ (> 20\%), indicates that the scale is unidimension. Based on the DIF plots, there is only one item shows teaching experience bias (item no 15 , probability value $.486<5 \%$ ). In conclusion, ETS is recommended as an instrument to measure teachers' engagement in Indonesian inclusive educational context by considering teacher experience as a demographic variable.
\end{abstract}

Keywords: Rasch Model, Special Educational Needs, Teachers' Engagement.

\section{INTRODUCTION}

Increasing of the population of children with special needs from year to year has been reported in almost all countries [1]. This fact gives special attention to the world to provide equal rights for children with special needs, one of which is the right to get education. Non-discriminatory educational services must be accompanied by easy access to them. This reason is a consideration for developing a model for inclusive education.

International inclusive education is affirmed in the Salamanca statement and framework of action on special educational needs in 1994. The policy of inclusive education in Indonesia is contained in the Law of the Republic of Indonesia No. 20 of 2003, which is also a juridical foundation in the application of inclusive education. At the next level of regulation, the Minister of National Education Regulation No.70 of 2009 specifically describes inclusive education as an education delivery system that provides opportunities for all students without exception to participate in education or learn together at the nearest public school [2].

The implementation of inclusion in education brings new demands for teacher work. A change in the education system towards inclusion presents new challenges for teachers' roles. Several challenges that 
teachers face have been identified, which include: how to interact with students in a class, increase responsibilities for teacher in terms of how to prepare curriculum, assess students' learning, meet the learning needs of all students both special needs and regular students, socialise the values of inclusion and tolerance for non-students with special needs, parents, and society [3]

Not only the increased responsibility for the work of inclusive teachers, specifically in Indonesia, but there are also many obstacles faced in implementing inclusive education. Various obstacles faced by inclusive schools, including teacher ratios that are not proportional to the number of students at each class, the readiness and competence of teachers, especially the lack of learning facilities for students with special needs, negative attitudes and concerns from parents, to limited infrastructure [4][5]. Study from Tarnoto [6] also confirms that teachers in Indonesia also face a considerable challenge such as a lack of knowledge and adequate skills, as well as lack of facilities in implementing inclusive education.

The description of teacher working conditions in inclusive schools as above will affect the performance and attachment of teachers to their work. Previous research has reported that teacher engagement is an important variable of teacher work behavior that has an impact on the emergence of ownership and responsibility towards the success of inclusive education for students with special needs [7].

Teacher engagement is a state of mind that is positively related to a job from the teaching profession. The teacher who has engagement is characterized by devoting all the energy and attention to teaching, positive emotional response, level of warmth and commitment in relationships with students and colleagues [8]. The ETS developed by Klassen et.al consists of 4 dimensions: cognitive engagement (CE), emotional engagement (EE), social engagement with students (SES), and social engagement with colleagues (SEC). In the context of inclusive education, the construct of teacher engagement emphasizes how to describe a specific engagement to the teacher to his/her work as a teacher in inclusive school. Teacher engagement behavior is an important part of the process of learning. Based on a transactional framework in teaching or learning, all teacher behavior in carrying out the main task of teaching is a component in the learning process that affects each other with other variables in the context, input, and output components [9]. This is the reason why teacher engagement is important to learn.

The study conducted by Klassen et.al [8] has developed an engaged teacher scale (ETS). On its development, ETS has been used to measure the engagement of teachers in regular schools in the context British cultural. The validity test also used classical theory in psychometry. If we consider the description of the responsibilities and conditions faced by inclusive school teachers as described in the previous paragraph, it raises the question of whether ETS is still suitable to be used to measure teacher engagement in the Indonesian context.

This study was conducted to validate ETS in different educational settings and culture. In particular, this study will estimate the psychometric properties of ETS in the inclusive educational setting in the Indonesian context. Using the response item analysis with Rasch modeling, it is hoped that more detailed information will be obtained about the psychometric properties of ETS including unidimensionality test (representing construct validity), reliability item and person, and differential item function based on gender and teaching experience (length of work).

Measurements using a scale generally result in a nominal score or sequence. Method of analysis with using classical test theory treat the raw score as if interval or ratio scale, so that gives less accurate results. The Rasch model has its advantages can overcome the weaknesses found in classical test theory [10[[11][12]. In the Rasch model, the raw score in the form an odds ratio is logarithmically transformed into logit units which is an interval scale and linear. Thus the high trait owned individually or the level of difficulty the item will be more accurately estimated and comparable, because it has the same unit, namely logit [13]. In the context of inclusive education, information on the difficulty of questions will allow in identifying aspects that determine teacher engagement.

\section{METHOD}

Participants in the study were teachers of public inclusion schools with a total of 340 teachers from all regions in Indonesia. 
Table 1. Participant demographics

\begin{tabular}{|llccc|}
\hline & & \% & Mean & SD \\
\hline Gender & $\mathrm{M}$ & 24 & & \\
& $\mathrm{~F}$ & 76 & & \\
\hline Age & $25-40$ & 48 & 37.3 & 1.02 \\
& $>40$ & 52 & 44.6 & \\
\hline Teaching & $<5$ years & 40.8 & 4.62 & 0.82 \\
experience & $>5$ years & 59.2 & 8.11 & \\
\multicolumn{4}{l}{ M= Male; $F=$ Female $;$ SD $=$ Standar Deviation }
\end{tabular}

All participants filled out the 16 items ETS scale that had been translated (through the process of translating and back translating) online. Data analysis to estimate reliability and validity (internal structure) performed using Rasch modelling [13]. The Rasch analysis model is a math measurement model describes how unique the response is each individual against a specific item in instrument. The Rasch model is a part of response item theory that can provide information reliability is more specific to the item level and person [14]. Rasch Analysis done using software Winsteps version 3.75.0.

The Rasch analysis in this study mostly followed the procedure from [15] and conducted to test the validity of the internal structure includes: unidimensionality (index raw variance explained must be> 20\%); index raw variance unexplained (should be $<15 \%$ ); item fit (the item index fits the item criteria the misfit or outliers is the value of the outfit MNSQ received $0.5<\mathrm{MNSQ}<1.5$ ); reliability score (Cronbach's alpha item good>0.8), and the item's functionality differential (bias item probability criterion $<5 \%$ ) $[13,15]$.

\section{RESULT}

The following shows the results of the respective analyses:

\section{a. Test of unidimensionality}

(Principal Component Analysis) of the residuals, namely measuring the extent to which the instrument measures what it should be measuring. Estimated validity of Rasch modelling conducted through the unidimensionality test which uses the principle of analysis the main component Table 2 shows the results of the ETS unidimensionality test. The results of the measurement of raw variance data amounted to $45.4 \%$ (> 20\%) indicates that the minimum requirements unidimensionality categorized in very good value $[13,15]$. Variance should not exceed $15 \%$ and the estimated results indicate in $1^{\text {st }}$ contrast value of $6.6 \%$ with eigenvalue $<2$. It can be interpreted that the instrument is unidimensional.

\section{b. Item measurement}

Testing of each item in ETS is done to find out information regarding the item. Based on value logit can be seen that item 12 with the highest logit value is 1.30 which indicates that the item is an item most difficult for respondents to agree on. Item 12 contains the statement "At school, I care about the problems of my colleagues". On the contrary, most items easily agreed upon by respondents is an item 9 with a logit value (-.71). The statement in item 7 is "At school, I am committed to helping my colleagues". The two items, items 12 and 7, are items from the same dimension e.g. social engagement with colleagues (SEC). This is an interesting finding because teachers identify it is too difficult to agree to care but too easy to agree to help colleagues. Furthermore, fit items in Rasch modelling used to check which items what fits and what doesn't (misfit or outliers). Criteria used for checking for misfit items, including: 1) Value of MNSQ outfit accepted is $0.5<$ MNSQ $<1.5$ and 2) the value of the ZSTD outfit accepted is $-2.0<\mathrm{ZSTD}$ $<2.0$. Based on the criteria of Linacre (2007) where the MNSQ value is infit or outfit item more than 1.4 logits are said to be the misfit item which means that item is confusing [15]. From Table 3 it is known, items that are a misfit include: item 1, 10, and 11.

Item 1 "At school, I connect well with my colleagues"

Item 10 "I love teaching"

Item 11 "While teaching I pay a lot of attention to my work"

Table 2. Dimensions and Invariance in Dimensionality Test with Rasch

\begin{tabular}{|lclcc|}
\hline \multicolumn{2}{|c|}{ Raw variance explained } & \multicolumn{2}{c|}{ Raw unexplained variance } & Eigenvalue \\
\hline By measure & $45.4 \%$ & In $1^{\text {st }}$ contrast & $6.6 \%$ & 1.9 \\
By person & $29.2 \%$ & In $2^{\text {nd }}$ contrast & $6.1 \%$ & 1.8 \\
By items & $16.2 \%$ & In $3^{\text {rd }}$ contrast & $5.5 \%$ & 1.6 \\
& & In $4^{\text {th }}$ contrast & $4.9 \%$ & 1.4 \\
& & In $5^{\text {th }}$ contrast & $4.1 \%$ & 1.2 \\
\hline
\end{tabular}


Table 3. Item fit order

\begin{tabular}{|ccccccc|}
\hline \multirow{2}{*}{ Item } & Logit score & S.E & \multicolumn{2}{c}{ Infit } & \multicolumn{2}{c|}{ Outfit } \\
\cline { 3 - 7 } & & & MNSQ & ZSTD & MNSQ & ZSTD \\
\hline 1 & .41 & .12 & 1.55 & 4.47 & 1.41 & 3.3 \\
2 & .06 & .13 & .99 & -.1 & 1.10 & .8 \\
3 & -.26 & .13 & .59 & -4.3 & .70 & -2.2 \\
4 & -.47 & .14 & .54 & -4.9 & .49 & -3.9 \\
5 & -.05 & .13 & .77 & -2.3 & .71 & -2.3 \\
6 & .25 & .12 & .55 & -5.2 & .53 & -4.7 \\
7 & .55 & .12 & .97 & -.3 & 1.09 & .8 \\
8 & -.63 & .14 & 1.00 & .1 & .81 & -1.1 \\
9 & -.71 & .14 & 1.01 & .2 & .88 & -.6 \\
10 & .53 & .12 & 1.83 & 6.8 & 1.72 & 5.6 \\
11 & -.16 & .13 & .09 & -3.2 & .75 & -1.9 \\
12 & 1.30 & .11 & 1.51 & 4.8 & 1.63 & 5.9 \\
13 & -.52 & .14 & .79 & -1.9 & .90 & -.6 \\
14 & -.09 & .13 & .86 & -1.3 & 1.13 & 1.0 \\
15 & -.38 & .14 & 1.08 & .7 & 1.08 & .6 \\
16 & .19 & .12 & 1.15 & 1.4 & 1.41 & 1.2 \\
\hline S.E Standar Error measurement & MNSQ mean square, ZSTD = Z-standard &
\end{tabular}

$S . E=$ Standar Error measurement, $M N S Q=$ mean square, $Z S T D=Z$-standard

Table 4. Reliability item \& person

\begin{tabular}{|cccc|}
\hline & Item & Person & $\begin{array}{c}\text { Alpha Cronbach } \\
\text { (item-person interaction) }\end{array}$ \\
\hline Reliability & .93 & .72 & .94 \\
separation & 3.65 & 1.59 & \\
\hline
\end{tabular}

\section{c. Reliability item and person}

Based on Table 4, the value of person reliability is .72 while the value of the item reliability is .93 , it can be said that the consistency of the answers of the respondents where the quality is pretty good the items in the instrument are also special [16]. In addition to item and person's interaction reliability values are shown from a Rasch modelling, namely the Cronbach alpha value (measuring interaction reliability between person and item as a whole) is .94 and is in the good category once. Value of item separation $=3.65(>3)$ indicates the measurement level classified as very good [15]. The interpretation of this separation values is that items from ETS can categorise participants based on their level of engagement in more detail. Score separation 1.57 or rounded up to be 2 meet the minimum value of separation so it can be accepted and shows which measurement level well [15].

\section{d. Differential item functioning}

To test for biased items, used the item functionality index differential (DIF index) by item criteria said to be biased if the item probability value $<5 \%$ (15). Figure 2 confirms that item 15 shows different responses to teachers who have teaching experience of less than 5 years and more than 5 years. The statement of item 15 in ETS was "While teaching, I work with intensity".

This study examined the construct validity of the 16-item of ETS scale using a Rasch analysis. The application of the Rasch model indicated that the ETS scale was unidimensional. Reliability Alpha Cronbach interaction item person (0.94) shows that ETS is a reliable scale. However, there are several items that should be considered for adaptation because they are misfit identified (item 1, 10, 11). 


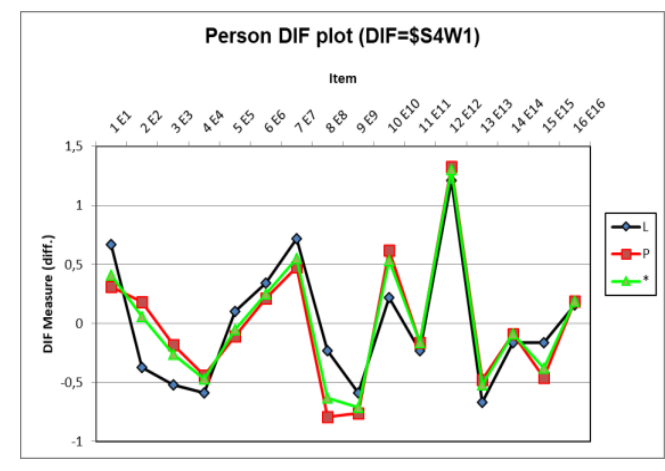

Figure 1. Graphic of DIF based on gender

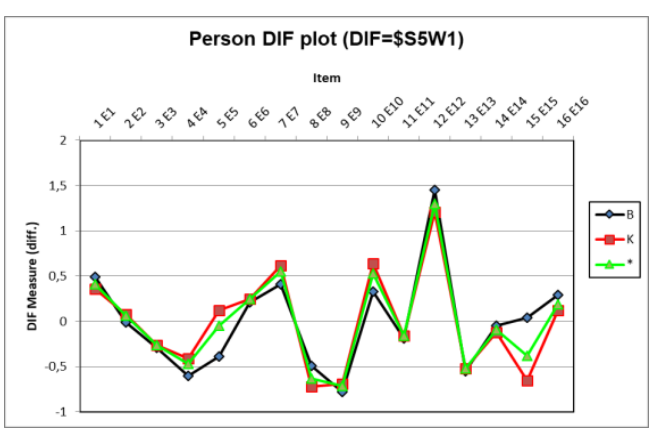

Figure 2. Graphic of DIF based on teaching experience

These items were considered confusing by respondents. This may be because the sentences used are not clear or do not represent the conditions of teachers in the context of inclusive education in Indonesia. Here are sentences of misfit items:

Item 1 "At school, I connect well with my colleagues"

\section{Item 10 "I love teaching"}

Item 11 "While teaching I pay a lot of attention to my work"

According to some studies most teachers who teach students with special needs in the class considered his work to be full of challenges, demanding patience height, tolerance, empathy, acceptance, and a positive attitude [17,18]. Some studies reports that it is not uncommon for teachers to be faced with unpredictable situations and have to hold back emotions [19-21]. For example when dealing with students suddenly rampage, oppose, tantrum, aggression or attack [3]. A study reported that teachers in Indonesia too facing another considerable challenge, such as a lack of knowledge, adequate skills and facilities in the implementation of inclusive education [6]. Another challenges such as using the interactive effects demand-control model perspective, complex demands without being accompanied by an increase personal resources (for example: knowledge and skills) in doing control over your job as a teacher will trigger a psychological stress reaction [22][23]. Work stress experienced by teachers is very likely to make teachers not focus on work, irritability [24] and decrease teacher's wellbeing [25][26]. This explanation may underlie why these 3 items are misfit items when ETS is used in the context of teachers in Indonesia.

The 16 ETS items were invariant (without the DIF effect), indicating that the teacher with a similar level of engagement will get the same score regardless of gender differences [11,27], but not based on teaching experience. Item number 15 indicates potential differences in teacher responses in showing engagement based on teaching experience with the probability value $.0486(<5 \%)$ increases to $.1258(>5 \%)$. Discussion based on response differences teacher length of teaching is supported by the results previous research. Experience and training has been researched related and participatory determine the positive attitude of the teacher towards inclusion [28,29]. Attitude positive teachers towards inclusion can directing the intention to behave at work positive ones include bound behaviour towards inclusion [30]. More specifics, training, and development has researched helped determine teacher attachment [31,32]. Discussion based on response differences teacher experience is supported by the results previous research. Experience and training has been researched related and participatory determine the positive attitude of the teacher towards inclusion [28,29].

An interesting finding and requiring further research is that there are items that are considered the most difficult to approve and the easiest to approve. Based on value logit, item 12 showed the highest logit value (1.30) that indicates that the item is an item most difficult for respondents to agree on. This item can also be interpreted as the most powerful item that describes teacher engagement. On the contrary, most items easily agreed upon by respondents is an item 9 with a logit value (-.71). The two items measure the same dimension, namely social engagement to colleagues (SEC), in more detail, here is the statement 
Item 12 "At school, I care about the problems of my colleagues".

Item 7 "At school, I am committed to helping my colleagues".

Why teachers find it difficult to care to colleagues but it is easy to help if their colleagues have difficulties? Do teachers who care to colleagues describe teachers who are more engaged than teachers helping colleagues? This finding is interesting to be explored further. Helping may be considered easier to do than caring. It could be that the meaning of caring is deeper and harder for the teacher to do. The meaning of the word is closely related to culture. According to the Indonesian dictionary, caring is a word that has multiple meanings and multiple implementations [33]. Caring is defined as a way to connect other values based on a person's feelings of commitment and responsibility a nurturing way of relating to a valued other toward whom one feels a personal sense of commitment and responsibility. Referring to the definition from the Indonesian dictionary, caring has consequences that are more difficult to do than just help. There are strong emotional nuances for someone who cares about others.

\section{Conclusion and implications}

Some of the findings above indicate that the use of ETS needs to consider the context. Educational or school contexts have implications for teacher duties and cultural contexts that have implications for the meaning and responses of teachers to items, thus, an adaptation process is required if using ETS in different contexts

Several implications can be drawn from the results. The psychometric properties of the 16 item ETS is good, indicating that it is suitable and ready for use with teachers in the context inclusive education in Indonesia. Additionally, the study results ranked the characteristic in terms of difficulty and relevance to engagement. Understanding the different degrees of difficulty of the characteristic included in the ETS may helpful in designing system, curricula, training programs to develop the behaviour of teachers to be successful in inclusive education. Characteristic ranked as higher in difficulty might require more concentration in-service training to ensure that teachers increase their caring ability to their work environment. Caring for colleagues is important to generate social support in the workplace and a sense of belonging, which will have an impact on each teacher again. The implementation of inclusive education requires an inclusive environment including mutual support and collaboration between teachers and all school members. Therefore, further studies by adapted ETS with consider the different context may help to confirm these study findings.

\section{AUTHORS' CONTRIBUTION}

IFK conceptualised the study, acquired the funding, analysed the data, and wrote the manuscript.

ES contributed on scientific thought to the discussion, make a layout

\section{ACKNOWLEDGMENT}

The authors would like to thank the owner of the ETS scale, Prof. Rob Klassen for giving permission to use his scale and having fruitful discussions with the author. The researcher also expressed his gratitude to all participants.

\section{REFERENCES}

[1] WHO. World report on disability 2011. Geneve; 2011.

[2] Ministry of National Education. Inclusive education training modules. Jakarta: Ministry of National Education; 2010.

[3] I.F. Kristiana, Fajrianthi, U. Purwono. Analisis Rasch dalam Utrecth work engagement scale-9 (UWES-9) versi bahasa Indonesia. J Psikol. 17(2) (2018) 204-17.

[4] T. Handayani, A.S. Rahadian. Better education for all: When we're included too. Masy Indones. 39(1) (2013) 27-48.

[5] Y. Sunardi, M, Gunarhadi, Priyono, J.L. Yeager. The implementation of inclusive education for students with special needs in Indonesia. Excell High Educ [Internet]. 15(2) (2011) 1-10. Available from: http://ehe.pitt.edu/ojs/index.php/ehe/article/view 127

[6] N. Tarnoto. Permasalahan-permasalahan yang dihadapi sekolah penyelenggara pendidikan inklusi pada tingkat SD. Humanit Indones Psychol J. 13(1) (2016) 50-61. 
[7] M.F. Giangreco, J.C. Suter, M.B. Doyle. Paraprofessionals in inclusive schools: A review of recent research. J Educ Psychol Consult [Internet]. 26(20) (2010) 41-57. Available from: http://www.tandfonline.com/doi/abs/10.1080/10 474410903535356

[8] R.M. Klassen, S. Yerdelen, T.L. Durksen. Measuring teacher engagement: Development of the engaged teachers scale (ETS). Front Learn Res [Internet]. 1(2) (2013) Available from:

http://journals.sfu.ca/flr/index.php/journal/articl e/view/44

[9] W.Huitt. A transactional framework of the teaching/learning process [Internet]. 2003 [cited 2019 Feb 26]. Available from: http://www.edpsycinteractive.org/materials/tchlr nmd.html

[10] M. Lee, J.J. Peterson, A. Dixon. Rasch calibration of physical activity self-efficacy and social support scale for persons with intellectual disabilities. Res Dev Disabil. 31 (2019) 203913.

[11] A. Tennant, P.G. Conaghan. The Rasch measurement model in rheumatology: What is it and why use it? When should it be applied, and what should one look for in a Rasch paper? Arthritis Rheum [Internet]. 57(8) (2007) 13581362. Available from: http://doi.wiley.com/10.1002/art.23108

[12] E.V. Smith Jr. Evidence for the reliability of measures and validity of measure interpretation: a Rasch measurement perspective. J Appl Meas. 2 (2001) 281-311.

[13] B. Sumintono, W. Widhiarso. Aplikasi model rasch untuk penelitian ilmu-ilmu sosial. Jakarta: Trim Komunikata; 2014.

[14] N.D. Verhelst. Item respons theories. In: Sanders PF, editor. Psychometrie in de praktijk. Arnhem: Cito Institute for Test Development; 1993.

[15] J.M. Linacre. A user's guide to WINTEPS Rasch-model computer programs. Chicago: MESA Press; 2007.
[16] T. Bond, C. Fox. Applying the Rasch model: Fundamental measurement in the human sciences. 2nd ed. New Jersey: LEA; 2007.

[17] K. Robertson, B. Chamberlain, C. Kasari. General education teachers' relationships with included students with autism. J Autism Dev Disord. 33 (2003) 123-30.

[18] M.L. Yell, A. Katsiyannis, E. Drasgow, M. Herbst. Developing legally correct and educationally appropriate programs for students with autism spectrum disorders. Focus Autism Other Dev Disabl [Internet]. 18(3) (2003) 18291. DOI: $10.1177 / 10883576030180030601$

[19] A.R. Hochschild. The managed heart: commercialization of human feeling. 3rd ed. Berkeley: University of California Press; 2012.

[20] S. Johnson, C. Cooper, S. Cartwright, I. Donald, P. Taylor, C. Millet. The experience of workrelated stress across occupations. J Manag Psychol [Internet]. 20(2) (2005) 178-187. DOI: 10.1108/02683940510579803/full/html

[21] S.A. Stansfeld, F.R. Rasul, J. Head, N. Singleton. Occupation and mental health in a national UK survey. Soc Psychiatry Psychiatr Epidemiol [Internet]. 46(2) (2011) 101-110. DOI: $10.1007 / \mathrm{s} 00127-009-0173-7$

[22] R.A.Karasek. Job demands, job control, and mental strain: Implications for job redesign. Adm Sci Q. 24 (1979) 285-308.

[23] C. Forlin. Inclusion: Identifying potential stressors for regular class teachers. Educ Res [Internet]. 43(3) (2001) 235-245. DOI: $10.1080 / 00131880110081017$

[24] P. Thukral. Work \& stress: A general overview. Int J Innov Res Adv Stud. 4(6) (2017) 454-458.

[25] E. Boujut, A. Dean, A. Grouselle, E. Cappe . Comparative Ssudy of teachers in regular schools and teachers in specialized schools in France, working with students with an sutism spectrum sisorder: Stress, social support, coping strategies and burnout. J Autism Dev Disord [Internet]. 46(9) (2016) 2874-2889. DOI: $10.1007 / \mathrm{s} 10803-016-2833-2$ 
[26] R.C. Whitaker, T. Dearth-Wesley, R.A. Gooze. Workplace stress and the quality of teacherchildren relationships in Head Start. Early Child Res Q [Internet]. 30 (2015) 57-69. Available from:

https://linkinghub.elsevier.com/retrieve/pii/S088 5200614000891

[27] A.H. Alnahdi. Rasch validation of the Arabic version of the lower extremity functional scale. Disabil Rehabil [Internet]. 40(3) (2018) 353359. DOI: 10.3389/fpsyg.2019.02345/full

[28] E. Avramidis, E. Kalyva. The influence of teaching experience and professional development on Greek teachers' attitudes towards inclusion. Eur J Spec Needs Educ [Internet]. 22(40) (2007) 367-389. DOI: $10.1080 / 08856250701649989$

[29] K. MacFarlane, L.M. Woolfson. Teacher attitudes and behavior toward the inclusion of children with social, emotional and behavioral difficulties in mainstream schools: An application of the theory of planned behavior. Teach Teach Educ [Internet]. 29 (2013) 46-52. Available from: https://linkinghub.elsevier.com/retrieve/pii/S074 2051X12001321

[30] I. Ajzen. Attitudes, personality and behavior. 2nd ed. New York: Open University Press; 2005.

[31] A.B. Bakker, M.P. Bal. Weekly work engagement and performance: A study among starting teachers. J Occup Organ Psychol [Internet]. 83(1) (2010) 189-206. DOI: $10.1348 / 096317909 X 402596$
[32] M.C. Altunela, O.E. Kocak, B. Cankir. The Eefect of job resources on work engagement: A study on academicians in Turkey. Educ Sci Theory Pract [Internet]. 2015; Available from: https://jestp.com/index.php/estp/article/view/69 0

[33] KKBI. Kamus besar bahasa Indonesia [Internet]. 2016. Available from: https://kbbi.kemdikbud.go.id/ 